\title{
High Power Continuous Wave Blue InAlGaN Laser Diodes Made by Plasma Assisted MBE
}

\author{
C. Skierbiszewski ${ }^{a, b, *}$, M. SiekACZ $^{a, b}$, P. Wiśniewski ${ }^{a, b}$, \\ P. Perlin ${ }^{a, b}$, A. FedunieWiCZ-ŻMuda ${ }^{b}$, G. CYWińsKi ${ }^{a}$, \\ J. SmalC ${ }^{a}$, S. Grzanka ${ }^{a, b}$, I. Grzegory ${ }^{a, b}$, M. LeSzCZyński ${ }^{a, b}$ \\ AND S. POROWSKI ${ }^{a}$ \\ ${ }^{a}$ Institute of High Pressure Physics, Polish Academy of Sciences \\ Sokołowska 29/37, 01-142 Warszawa, Poland \\ ${ }^{b}$ TopGaN Ltd., Sokołowska 29/37, 01-142 Warszawa, Poland \\ Room temperature, continuous wave operation of InGaN multi-quantum \\ wells laser diodes made by rf plasma assisted molecular beam epitaxy at \\ $411 \mathrm{~nm}$ wavelength is demonstrated. The threshold current density and \\ voltage were $4.2 \mathrm{kA} / \mathrm{cm}^{2}$ and $5.3 \mathrm{~V}$, respectively. High optical power output \\ of $60 \mathrm{~mW}$ was achieved. The lifetime of these laser diodes exceeds $5 \mathrm{~h}$ with \\ $2 \mathrm{~mW}$ of optical output power. The laser diodes are fabricated on low dis- \\ location density bulk GaN substrates, at growth conditions which resembles \\ liquid phase epitaxy. We demonstrate that relatively low growth temper- \\ atures $\left(600-700^{\circ} \mathrm{C}\right)$ pose no intrinsic limitations for fabrication of nitride \\ optoelectronic components by plasma assisted molecular beam epitaxy.
}

PACS numbers: 42.55.Px, 85.35.Be, 42.60.By, 73.21.Cd

\section{Introduction}

The major achievements and developments in a field of the short wavelength InGaN emitters has been made by metal organic vapor phase epitaxy (MOVPE) technique $[1,2]$ and until very recently molecular beam epitaxy (MBE) was not regarded as a valuable technology for nitride optoelectronic devices. It was believed that successful MBE growth of device-quality nitride structures requires high growth temperatures close to those used in MOVPE (e.g. as high as

*corresponding author; e-mail: czeslaw@unipress.waw.pl 
$1050-1100^{\circ} \mathrm{C}$ for GaN — equal to a half of GaN melting temperature $\left.[3,4]\right)$. However, in vacuum conditions, the GaN substrate at temperatures above $800^{\circ} \mathrm{C}$ starts to decompose and matching overpressure of active nitrogen species is needed to stabilize the surface and to promote the growth of the layer. In MOVPE, ammonia overpressure in the range of 100 mbar- 1 bar prevents GaN decomposition for temperatures in excess of $1000^{\circ} \mathrm{C}$. For MBE, which relies on the negligible interaction of the atomic beams, such conditions are unattainable. Still, some groups working in the nitrides managed to push the growth conditions in the MBE reactors fairly close to these used in the MOVPE by growing at temperatures as high as $1000^{\circ} \mathrm{C}$ (using very high ammonia flows - up to $200 \mathrm{sccm}$ ) and demonstrate of blue laser diodes (LDs) (cw operation at $\approx 0.2 \mathrm{~mW}$ optical power for 3 minutes) [5]. In spite of its potential advantages for both optoelectronic [6] and electronic [7] devices, corrosive nature of ammonia creates additional hazards and technological challenges as well as leads to often undesirable high hydrogen background during the epitaxial process.

In this work a different approach for nitride epitaxy is described. We will demonstrate that device quality structures can be successfully deposited by ammonia free, plasma assisted MBE (PAMBE) at growth temperatures much below $800^{\circ} \mathrm{C}$ at growth conditions similar to liquid phase epitaxy. In PAMBE the active nitrogen is generated from $\mathrm{N}_{2}$ molecules in rf plasma cell. Recent progress in understanding growth of nitrides in PAMBE led to several important achievements in a field of $\mathrm{GaN} / \mathrm{AlGaN}$ heterostructures [8-10], light emitting diodes (LEDs) [11] and pulse LDs $[12,13]$. It was evidenced experimentally that it is possible to achieve step-flow growth mode at temperatures below $800^{\circ} \mathrm{C}$ at group III rich conditions, when thin dynamic Ga (or In) layer is formed on the surface [14-17]. This finding was confirmed by first principle ab initio calculations, where substantial reduction of barrier for $\mathrm{N}$ adatoms diffusion was shown (e.g. from $1.3 \mathrm{eV}$ for clean GaN surface to $0.5 \mathrm{eV}$ when GaN surface is covered by In monolayer) [18]. We demonstrate first continuous wave (cw) LDs grown by plasma assisted MBE.

\section{Experiment and results}

The growth was performed in custom made VG90 Oxford MBE reactor equipped with Veeco rf plasma source. The rf plasma source was operating at $240 \mathrm{~W}$ for $0.8 \mathrm{sccm} \mathrm{N}_{2}$ flow controlled by mass flow controller. The structures were deposited on (0001) Ga-polarity side of the conductive, low dislocation density $\left(\approx 100 \mathrm{~cm}^{-2}\right.$ ) high pressure grown GaN bulk substrates. The epi-ready bulk substrates were prepared in the three-step process of mechano-polishing, dry etching and deposition of $2 \mu \mathrm{m}$ GaN:Si buffer layer in the MOVPE reactor. In Fig. 1 structure details are shown. The $40 \mathrm{~nm}$ GaN:Si buffer layer and $450 \mathrm{~nm}$ $\mathrm{Al}_{0.08} \mathrm{Ga}_{0.92} \mathrm{~N}$ :Si cladding were grown at gallium rich conditions at temperature $720^{\circ} \mathrm{C}[16]$. The bottom waveguide, multiquantum wells (MQWs), top waveguide, top cladding and contact layer were grown at indium rich conditions at $600^{\circ} \mathrm{C}$. 


\begin{tabular}{|c|c|}
\hline \multirow{3}{*}{ Contact layer } & \\
\hline & $3 \mathrm{~nm} \mathrm{In} \operatorname{In}_{0.18} \mathrm{Ga}_{0.82} \mathrm{~N}: \mathrm{Mg}$ \\
\hline & $14 \mathrm{~nm} \operatorname{In}_{0.02} \mathrm{Ga}_{0.98} \mathrm{~N}: \mathrm{Mg}$ \\
\hline Top cladding & $\begin{array}{l}2.5 \mathrm{~nm} \mathrm{In}_{0.02} \mathrm{Ga}_{0.98} \mathrm{~N}: \mathrm{Mg} \quad x \quad 60 \\
2.5 \mathrm{~nm} \mathrm{In}_{0.02} \mathrm{Al}_{0.16} \mathrm{Ga}_{0.82} \mathrm{~N}: \mathrm{Mg}\end{array}$ \\
\hline Waveguide - top & $70 \mathrm{~nm} \mathrm{In}_{0.02} \mathrm{Ga}_{0.98} \mathrm{~N}: \mathrm{Mg}$ \\
\hline Blocking layer & $14 \mathrm{~nm} \mathrm{In} \mathrm{In}_{0.02} \mathrm{Al}_{0.16} \mathrm{Ga}_{0.82} \mathrm{~N}: \mathrm{Mg}$ \\
\hline MQW & 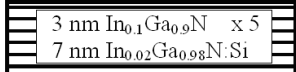 \\
\hline Waveguide - bottom & $\begin{array}{c}100 \mathrm{~nm} \mathrm{In}_{0.02} \mathrm{Ga}_{0.98} \mathrm{~N} \\
40 \mathrm{~nm} \mathrm{GaN}\end{array}$ \\
\hline Bottom cladding & $450 \mathrm{~nm} \mathrm{Al} \mathrm{Al}_{0.08} \mathrm{Ga}_{0.92} \mathrm{~N}: \mathrm{Si}$ \\
\hline Buffer layer & $40 \mathrm{~nm}$ GaN:Si \\
\hline Substrate & $\begin{array}{l}2 \mu \mathrm{m} \text { GaN MOVPE buffer } \\
\text { Bulk GaN substrate }\end{array}$ \\
\hline
\end{tabular}

Fig. 1. Laser diode structure details.

The active region consists of five $3 \mathrm{~nm} \operatorname{In}_{0.1} \mathrm{Ga}_{0.9} \mathrm{~N}$ wells with $7 \mathrm{~nm} \operatorname{In}_{0.02} \mathrm{Ga}_{0.98} \mathrm{~N}$ barriers.

The devices were processed as ridge-waveguide, oxide-isolated lasers. The mesa structure was etched out in the wafer down to the depth of $0.3 \mu \mathrm{m}$. The laser structure was then isolated by e-beam deposition of a $0.2 \mu$ m layer of $\mathrm{ZrO}_{x}$. The $20 \mu \mathrm{m}$ wide and $500 \mu \mathrm{m}$ long stripes were used for the laser resonators. The oxidized $\mathrm{Ni} / \mathrm{Au}$ ohmic contacts were deposited on the top surface of the device, while $\mathrm{Ti} / \mathrm{Au}$ contacts were deposited on the backside of the highly conducting $n$-GaN substrate crystal. The cleaved laser mirror facets were coated by symmetrically reflecting mirrors. Figure 2 shows the light-current-voltage $(L-I-V)$

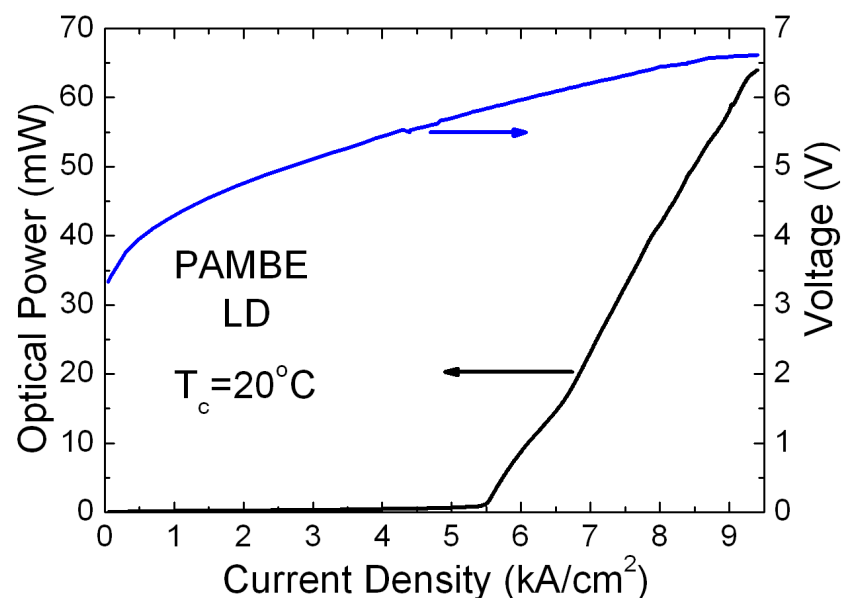

Fig. 2. The light-current-voltage characteristic of 5 MQW LD at room temperature. 
characteristics of the representative LDs. The laser action was registered at the lowest threshold current density and voltage of $4.2 \mathrm{kA} / \mathrm{cm}^{2}$ and $5.3 \mathrm{~V}$, respectively. The reduction of the operating voltage in comparison with our earlier LDs $[12,13]$ was possible after replacement GaN:Mg by $\operatorname{In}_{0.02} \mathrm{Ga}_{0.98} \mathrm{~N}: \mathrm{Mg}$ contact layer. The InGaN alloy has lower acceptor activation energy than GaN, therefore for the same $\mathrm{Mg}$ impurity content, the hole concentration in InGaN is higher than in GaN. The hole concentration measured on $\mathrm{In}_{0.02} \mathrm{Ga}_{0.98} \mathrm{~N}$ reference layers was $4 \times 10^{18} \mathrm{~cm}^{-3}$ in comparison to $5 \times 10^{17} \mathrm{~cm}^{-3}$ on GaN [19]. In addition, $3 \mathrm{~nm} \operatorname{In}_{0.18} \mathrm{Ga}_{0.82} \mathrm{~N}$ capping layer was used to lower resistance of the $p$-type ohmic contact due to the polarization effects [20]. The maximum optical power obtained for our lasers was $60 \mathrm{~mW}$ (30 mW per facet) and differential gain $\eta=0.19 \mathrm{~W} / \mathrm{A}$. The wide stripe geometry results in the multimode lasing (see Fig. 3). The lasing operation at $2 \mathrm{~mW}$

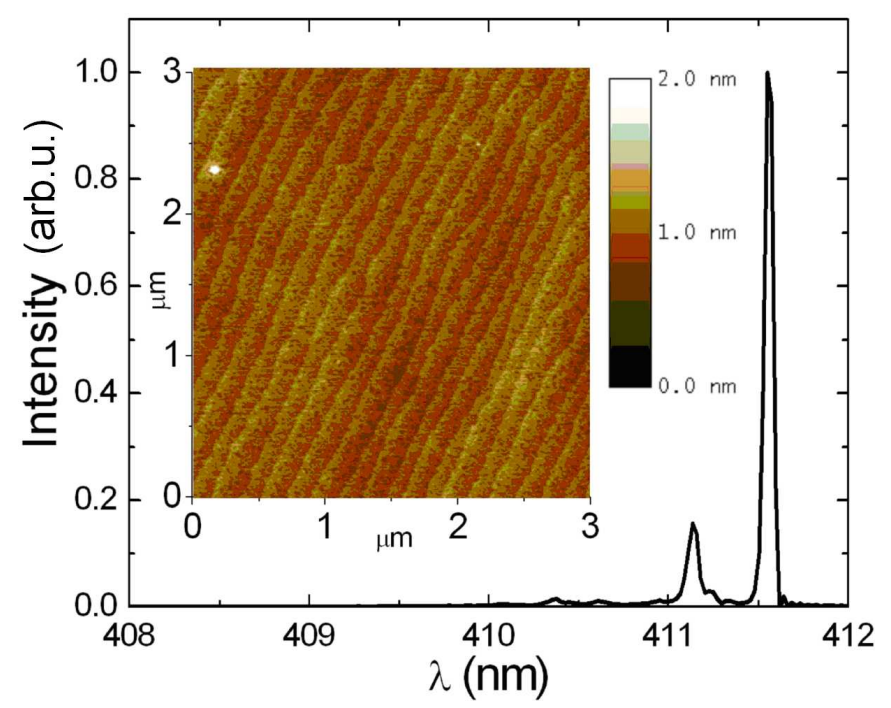

Fig. 3. The emission spectrum of the laser diode operating above lasing threshold. Inset shows atomic force microscopy image of $\operatorname{In}_{0.02} \mathrm{Ga}_{0.98} \mathrm{~N}$ layer grown at $600^{\circ} \mathrm{C}$.

( $1 \mathrm{~mW} /$ per facet) of optical output power for one of our LDs exceeds 5 hours. The laser operation was demonstrated at temperature range $20-32^{\circ} \mathrm{C}$ (Fig. 4). From the activation dependence of $I_{\mathrm{th}}$, according to equation $I_{\mathrm{th}}=I_{0} \exp \left(T / T_{0}\right)$, the characteristic temperature $T_{0}$ can be found. This temperature is determined by nonradiative recombination, current overflow and other thermally activated processes in LDs. The $T_{0}$ determined from temperature dependence of lasing threshold for cw mode of our LDs was $83 \mathrm{~K}$. It is still far behind the best $T_{0}$ reported in the literature $(235 \mathrm{~K}[21])$ indicating that it is a space for further optimization of the electron blocking layer and QW system in our LDs.

As it was mentioned before, at group III metal rich regime one can create conditions for two-dimensional step flow growth mode, which in principle should give 


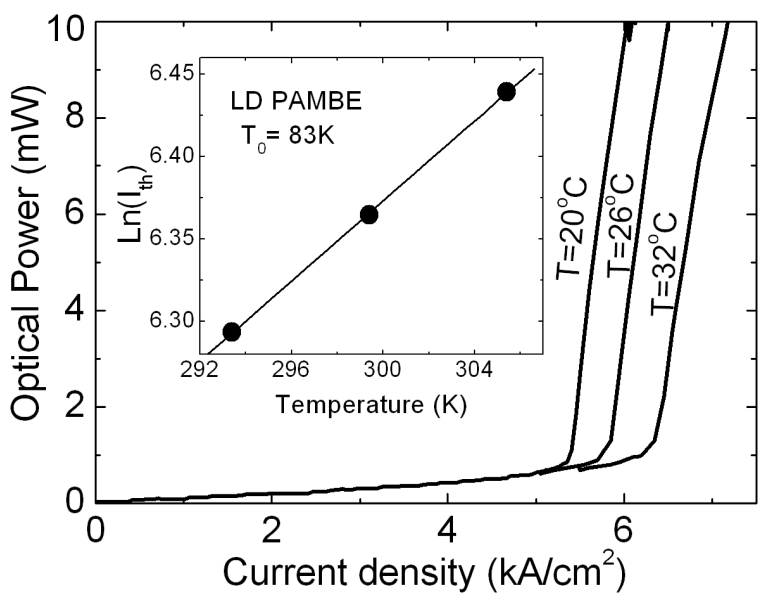

Fig. 4. The temperature dependencies of light-current characteristic. Inset shows values of threshold current $I_{\text {th }}$ as a function of temperature.

device quality structures by PAMBE. However, until very recently the efficiency of InGaN QWs grown by PAMBE was far behind those obtained by MOVPE. The poor quality of InGaN QWs from PAMBE was related with the growth on high dislocation density substrates. In that case, the dominant growth mode is dislocation mediated growth mechanism which results in spiral morphology [22]. Spiral growth leads to formation of hillocks which can change properties of InGaN QWs e.g. it can be a source of In segregation and InGaN alloy fluctuation along the QWs. The evolution of such spirals during growth, their radius and hillocks height depend strongly on the growth conditions - temperature and III/V ratio $[23,24]$. Unfortunately for PAMBE technique, the growth window with dynamically stable liquid $\mathrm{Ga}$ (or In) layer is very narrow - it requires precise tuning of growth rate, temperature and Ga (In) fluxes [14-16]. Therefore (unlike MOVPE), there is almost no freedom to vary III to V ratio in order to change surface morphology. The situation for MBE growth of nitrides on low dislocation density GaN substrates is different. If the low dislocation density substrate is used, the two-dimensional step flow growth mode with parallel atomic steps is observed even at low growth temperatures and atomically flat surfaces and therefore smooth interfaces required for LDs are obtained (see inset to Fig. 3). Other crucial element in this work was optimization of the optical quality of the quantum wells by fine-tuning the growth parameters to maximize the room temperature photoluminescence (PL) intensity and to minimize full width at half maximum (FWHM) of the PL lines. We find that peak PL intensities for our optimized test 10-period $\mathrm{In}_{x} \mathrm{Ga}_{1-x} \mathrm{~N} / \mathrm{In}_{0.02} \mathrm{Ga}_{0.98} \mathrm{~N}$ MQW structures grown on bulk GaN substrates cover spectral range from 385 to $520 \mathrm{~nm}$ (see Fig. 5). Equally important are very small values for FWHM of the measured PL lines, varying from $7 \mathrm{~nm}$ (for PL line at $385 \mathrm{~nm}$ ) to $35 \mathrm{~nm}$ (for PL line at $520 \mathrm{~nm}$ ) with increasing In content in the QW 


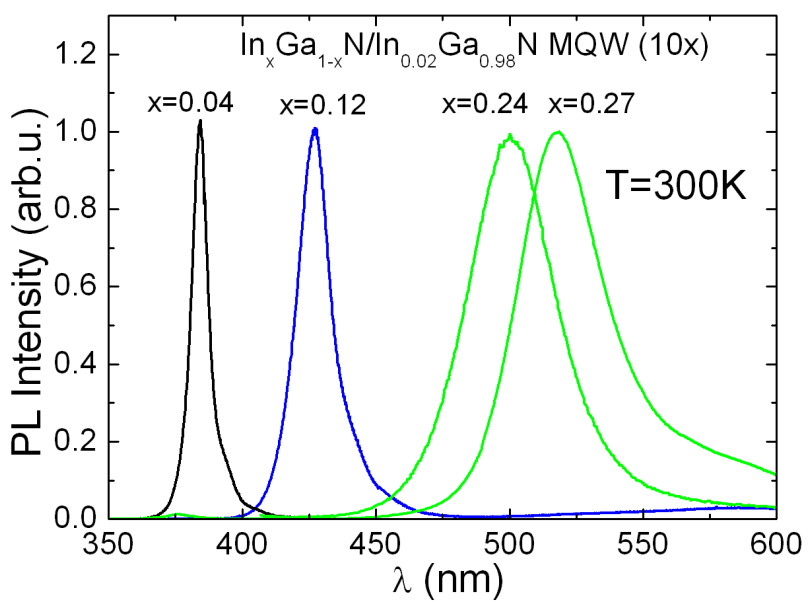

Fig. 5. Photoluminescence spectra of $\operatorname{In}_{x} \mathrm{Ga}_{1-x} \mathrm{~N} / \mathrm{In}_{0.02} \mathrm{Ga}_{0.98} \mathrm{~N}$ multi-quantum wells at $T=300 \mathrm{~K}$. The indium content $x$ is equal to $0.04,0.12,0.24$, and 0.27 , respectively.

from $4 \%$ to $27 \%$ (see Fig. 5). The FWHM can be influenced by a number of factors, such as uniformity of In composition in the wells, uniformity of In composition from well to well and the quality of the interfaces.

In conclusion, we demonstrate continuous wave, high power blue-violet laser diodes operating at room temperatures made by PAMBE. The structures were deposited on low dislocation density bulk GaN substrates. The $60 \mathrm{~mW}$ optical power is achieved and the lifetime of these LDs exceeds 5 hours for $2 \mathrm{~mW}$ of output power. The use of low dislocation density substrates eliminates spiral morphology and substantially enlarge "growth window" for device quality structures. The growth of InGaN at low temperatures allows to achieve efficient PL in the UVgreen range (385-520 nm). Therefore low temperature PAMBE technology opens new perspectives for next generation of InGaN based high power laser diodes.

\section{Acknowledgments}

This work was partially supported by the Ministry of Science and Higher Education grant No. 3T11B04729.

\section{References}

[1] S. Nakamura, M. Senoh, S.-I. Nagahama, N. Iwasa, T. Yamada, T. Matsushita, H. Kiyoku, Y. Sugimoto, T. Kozaki, H. Umemoto, M. Sano, K. Chocho, Appl. Phys. Lett. 73, 832 (1998).

[2] M. Kneissl, D.P. Bour, C.G. Van de Walle, L.T. Romano, J.E. Northrup, R.M. Wood, M. Teepe, N.M. Johnson, Appl. Phys. Lett. 75, 581 (1999).

[3] A. Ishizaka, Y. Murata, J. Phys., Condens. Matter 6, L693 (1994).

[4] W. Utsumi, H. Saitoh, H. Kaneko, T. Watanuki, K. Aoki, O. Shimomura, Nature Mater. 2, 735 (2003). 
[5] M. Kauer, S.E. Hooper, V. Bousquet, K. Johnson, C. Zellweger, J.M. Barnes, J. Windle, T.M. Smeeton, J. Heffernan, Electron. Lett. 41, 23 (2005).

[6] N. Grandjean, B. Damilano, J. Massies, J. Phys., Condens. Matter 13, 6945 (2001).

[7] J.A. Bardwell, Y. Liu, H. Tang, J.B. Webb, S.J. Rolfe, J. Lapointe, Electron. Lett. 39, 564 (2003).

[8] M.J. Manfra, K.W. Baldwin, M. Sergent, R.J. Molnar, J. Caissie, Appl. Phys. Lett. 85, 1722 (2004).

[9] I.P. Smorchkova, L. Chen, T. Mates, L. Shen, S. Heikman, B. Moran, S. Keller, S.P. DenBaars, J.S. Speck, U.K. Mishra, J. Appl. Phys. 90, 5196 (2001).

[10] C. Skierbiszewski, K. Dybko, W. Knap, J. Łusakowski, M. Siekacz, W. Krupczyński, G. Nowak, M. Boćkowski, Z. Wasilewski, D. Maude, T. Suski, S. Porowski, Appl. Phys. Lett. 86, 102106 (2005).

[11] P. Waltereit, H. Sato, C. Poblenz, D.S. Green, J.S. Brown, M. McLaurin, T. Katona, S.P. DenBaars, J.S. Speck, J.-H. Liang, M. Kato, H. Tamura, S. Omori, C. Funaoka, Appl. Phys. Lett. 84, 2748 (2004).

[12] C. Skierbiszewski, Z. Wasilewski, M. Siekacz, A. Feduniewicz, P. Perlin, P. Wisniewski, J. Borysiuk, I. Grzegory, M. Leszczynski, T. Suski, S. Porowski, Appl. Phys. Lett. 86, 011114 (2005).

[13] C. Skierbiszewski, P. Perlin, I. Grzegory, Z.R. Wasilewski, M. Siekacz, A. Feduniewicz, P. Wisniewski, J. Borysiuk, P. Prystawko, G. Kamler, T. Suski, S. Porowski, Semicond. Sci. Technol. 20, 809 (2005).

[14] B. Heying, I. Smorchkova, C. Poblenz, C. Elsass, P. Fini, S. DenBaars, U. Mishra, J.S. Speck, Appl. Phys. Lett. 77, 2885 (2000).

[15] C. Adelmann, J. Brault, D. Jalabert, P. Gentile, H. Mariette, Guido Mula, B. Daudin, J. Appl. Phys. 91, 9638 (2002).

[16] C. Skierbiszewski, Z. Wasilewski, M. Siekacz, A. Feduniewicz, B. Pastuszka, I. Grzegory, M. Leszczynski, S. Porowski, Phys. Status Solidi A 201, 320 (2004).

[17] G. Koblmuller, R. Averbeck, H. Riechert, P. Pongratz, Phys. Rev. B 69, 035325 (2004).

[18] J. Neugebauer, T.K. Zywietz, M. Scheffler, J.E. Northrup, H. Chen, R.M. Feenstra, Phys. Rev. Lett. 70, 56101 (2003).

[19] C. Skierbiszewski, Acta Phys. Pol. A 108, 635 (2005).

[20] Th. Gessmann, J.W. Graff, Y.-L. Li, E.L. Waldron, E.F. Schubert, J. Appl. Phys. 92, 3740 (2002).

[21] T. Mukai, S. Nagahama, T. Yanamoto, M. Sano, Phys. Status Solidi A 192, 261 (2002).

[22] B. Heying, E.J. Tarsa, C.R. Elsass, P. Fini, S.P. DenBaars, J.S. Speck, J. Appl. Phys. 85, 6470 (1999).

[23] H. Emmerich, C. Eck, Continuum Mech. Thermodynam. 17, 373 (2006).

[24] R.H. Swendsen, P.J. Kortman, D.P. Landau, H. Muller-Krumbhaar, J. Cryst. Growth 35, 73 (1976). 